\title{
Effect of Music with Brainwave Synchronizer on the Performance of Collegiate Throwing Athletes
}

\author{
Francis Mae L. Rebadomia ${ }^{1}$, Jeremiah Seag Miguel G. Amparo ${ }^{1}$, Jessa P. Reyes ${ }^{1}$, Alvin George C. Co- \\ bar $^{2}$ and Rhene A. Camarador ${ }^{1}$ \\ ${ }^{1}$ Polytechnic University of the Philippines, College of Human Kinetics, Manila, Philippines, ${ }^{2}$ Ateneo de Manila University, Basic Education Unit, \\ Quezon City, Philippines
}

\begin{abstract}
Brainwave entrainment has been a method used as a therapy to reduce anxiety and heighten concentration, facilitating brain to enter a specific state. In sports, brainwave alignment is facilitated as athletes utilized music in their pre-competition routines. The aim of this study is to know if wave-synchronized music influence power performance of collegiate athletes by gathering six $(\mathrm{N}=6)$ college throwers, 3 males and 3 females in a quasi-experimental research. Participants ranged from shotput, discus and javelin events. With reversal method, throwing performance data were collected for 11 days, with treatment days using both high (T1, T2, T4) and low (T3) frequency waves after every 2 untreated observations. Results show that synchronizing alpha waves $(12 \mathrm{~Hz})$ to music listened by athletes during warm-up leads to significant increase in throwing distances of participants compared to the untreated trial performance. On the other hand, synchronizing theta waves (0.5-3 $\mathrm{Hz}$ ) to music produced lower throwing distances significantly when compared to day-before and day-after observations. Throwing performance for the untreated observations also showed an increasing trend before the theta wave treatment day. However, no long-term effect of alpha waves was directly seen after the intervention as perceived in latter untreated observations. Further studies are needed to compare music with and without wave synchronizers or to compare the utilization of preferred music versus unfavored music during warm-up.
\end{abstract}

Key words: brainwave entrainment, throwing performance, arousal, alpha brainwave

\section{Introduction}

In competitions, the use of pre-match rituals is evident and believed to influence outcome of every individual athlete's performance. Aside from physical warm-up, athletes also listened to music of their choice as a pre-competition ritual. Athletes have previously reported to have done this on various events and help enforce a desirable performance. Not only used during warm-ups, athletes use the aid of music while in training sessions as well. This helped them in their motivation and emotions, leading to positive movement activation (Laukka \& Quick, 2013). In some observations, this method has altered performers' character and personality in the playing field. With self-selected music, participants' self-esteem has seen to be affected, resulting to a positive and desirable per- formance. This practice led to a character of greater risk taking among participants (Elvers \& Steffens, 2017). While drive and character of athletes are affected, differences between sexes in terms of responses to synchronous music is still observed (Karageorghis et al., 2010).

Between music and performance outcome, arousal and relaxation as a variable is being part of points for discussion. With the inverted $U$ principle, function is only realized on high-difficulty tasks and found to differ from one gender to the other. One study found in arousal measures that women are more reactive from contributing conditions to arousal (Bargh \& Cohen, 1978). Conversely for unfamiliar music being used, it is evident that both relaxing and arousing in nature decreased somatic anxiety, and only relaxing music decreased

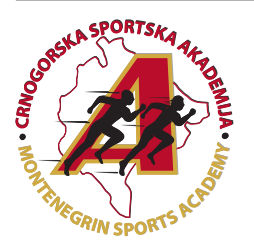

Correspondence:

A.G.C. Cobar

Ateneo de Manila University, Basic Education Unit, Quezon City, Philippines

E-mail: acobar@ateneo.edu 
cognitive anxiety. As cognition responds to relaxing music, self-confidence increase was also observed (Kuan, Morris, Kueh, \& Terry, 2018).

In the inverted $\mathrm{U}$, the zone of optimal functioning $(\mathrm{ZOF})$ is observed to be the most efficient variant of this hypothesis and found to be closely associated with the performance and outcome (Turner \& Raglin, 1996). Achieving ZOF through music in sport often aims to improve athlete's well-being, the same way physical and psychological techniques influenced mood (Cobar, Borromeo, Agcaoili, \& Rodil, 2017) and performance. In the study of Pelka et al. (2017), systematic breathing as intervention was also considered as a technique for relaxation, showing its interacting effects with running performance, specifically sprinting speed with better results than controlled groups.

\section{Brainwave Entrainment and Arousal}

Brainwave entrainment (BWE), being considered as a latent factor in music is known to reduce anxiety for both traitand state-type significantly (Alipoor, Oraki, \& Sabet, 2014). It was observed in a study that there was a heightened cognitive task performance specifically in learning time, complex navigational and decision-making abilities, when BWE is employed (Argento et al., 2017). For both, it possesses positive influence on the psycho-emotional make-up of an individual. Findings also suggested BWE as an effective therapeutic tool for people suffering from cognitive functioning deficits, pain, stress, headaches, PMS, and behavioral problems (Huang, 2008). However, this study by Huang (2008) suggested more trials for future researches and additional protocols with outcome.

As a significant mechanism in aiding athletes to reach a specific state, BWE become common in altering athletes' level of arousal and concentration. The interaction of arousal and stress response has been found to be favorable also for cardiovascular reactivity and higher self-confidence (Sammy et al., 2017). The effect of frequency of soundwave to concentration of athletes varies whether it is low or high for alpha or theta waves sensed by an athlete is seen to be connected with the level of relaxation and concentration state (Aris, Lias, \& Taib, 2010). The functional system for excitatory and inhibitory processes was revealed through the inclusion of different frequency of waves in Hertz $(\mathrm{Hz})$ and its association with arousal and wakefulness (Robinson, 2000). These were found in studies not only using sound but also light waves, and its association not only with alertness (Viola, James, Schlangen, \& Dijk, 2008) but in effecting positive change in cognition (Cruceanu \& Rotarescu, 2013). In one study, soundwaves at $2-8 \mathrm{~Hz}$ were used and found to affect participants' perceived sleep quality and after-sleep state positively when done in eight weeks (Abeln, Kleinert, Strüder, \& Schneider, 2013). This specific function of wave frequency validated the effect of entrainment in individuals' behavior (Stinson \& Arthur, 2013).

\section{Soundwaves on Performance}

The use of music as a motivational tool in exercise and sports performance has produced mixed findings. A study showed that the use of musical aid with no direct inclusion of soundwaves is found have better influence on cardiovascular exercise (K. Brooks \& K. Brooks, 2010). It proved also that motivational music benefited athletes' performance in terms of exhaustion time and in the use of oxygen. The prominence of beat and tempo, and how it manifests in movements showed more importance than music preference (Terry, Karageorghis, Saha, \& D' Auria, 2012). Making rhythm-specific factors come in during warm-up found to significantly increase power output of well-trained athletes when motivational music was used, this is found in both peak and mean power with a Wingate test (Jarraya et al., 2012). For sports that focuses on fine motor skills like archery, performance improved by listening to relaxing music, and was associated with the greatest gain in performance with lowest physiological arousal (Kuan et al., 2018). These mixed findings reported included type of music, relaxing or arousing, and depending on the type of sport performance need to be aided, without noting special focus on soundwave synchronization.

Brainwave synchronization has been hypothesized in this study to be a factor in past studies' mixed findings. From physical performance, specific brain frequency has also been associated with open-ended creative problem performance $(\mathrm{Li}$, Tseng, Tsai, Huang, \& Lin, 2016). The dynamics between alpha and beta waves varied when open- or closed-ended creativity tasks are concerned. The specificity of wave synchronicity has produced specific and positive performance outcome, making practitioners use them with music resulting to better performance among non-elite practitioners (Simpson \& Karageorghis, 2006). This idea made the application to be very specific to the nature of the sport. Specifically for field throwing events, athletes should be inclined to optimal arousal and concentration during competitions (Judge, Bell, Bellar, \& Wanless, 2010), and appropriate entrainment aid should be taking in to consideration.

Mixed findings were noted with regards to investigating the direct effects of music in general to the actual sports performance among reasons are soundwaves in music being taken out of consideration. While the researchers recognize the benefit of pre-competition music exposure, they aim to know if soundwaves in music directly influence the performance of college throwers, utilizing alpha waves in particular. The investigation was delimited to the effect of soundwave frequency in music to throwing and did not scope effects brought by desirable nor undesirable type of music used before the throws. Findings derived from this study can support the supply for an alternative, psychological ergogenic aid for collegiate athletes.

\section{Methods \\ Participants}

The researchers accumulated six $(\mathrm{N}=6)$ college throwers, three (3) males and three (3) females with mean age (years) of 19.33, who are members of university competing team. Participants do not have hearing disorders.

\section{Instrumentations}

Throwing Implements - The researchers prepared materials for data collection such as javelin $(M=800 \mathrm{~g}$; $\mathrm{W}=600 \mathrm{~g})$, shotput $(M=7 \mathrm{~kg} ; \mathrm{W}=4 \mathrm{~kg})$ and discus $(M=2 \mathrm{~kg} ; \mathrm{W}=1 \mathrm{~kg})$, with standards used in athletics tournaments, throwing events.

Stanley Measuring Tape $(50 \mathrm{~m})$ - Researchers used a tape as a tool to measure the throwing distances of participants (Figure 1). The instrument is made from a plastic material, ranging from 0 to $50 \mathrm{~m}$ 


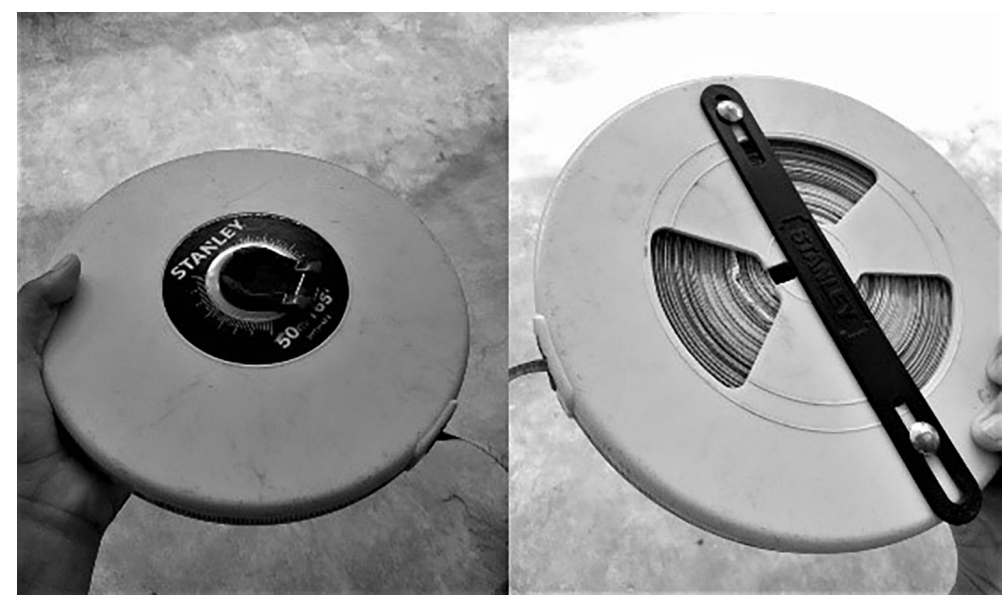

Figure 1. Distance Measuring Device

Wave-synchronized Music - The music used in the treatment sessions has standard of Alpha and Beta $(12 \mathrm{~Hz})$ brainwaves, and Theta $(0.5-3 \mathrm{~Hz})$ brainwaves downloaded on the web.

Omron ${ }^{\oplus}$ Body Fat Handheld Monitor (HBF-306) - The handheld bioelectric impedance device (Figure 2) was used for demographic purposes. It was shown to be a tool in assessing body composition as validated and used in previous experimental studies (Moulton, 2013; Cobar \& Madrigal, 2016).

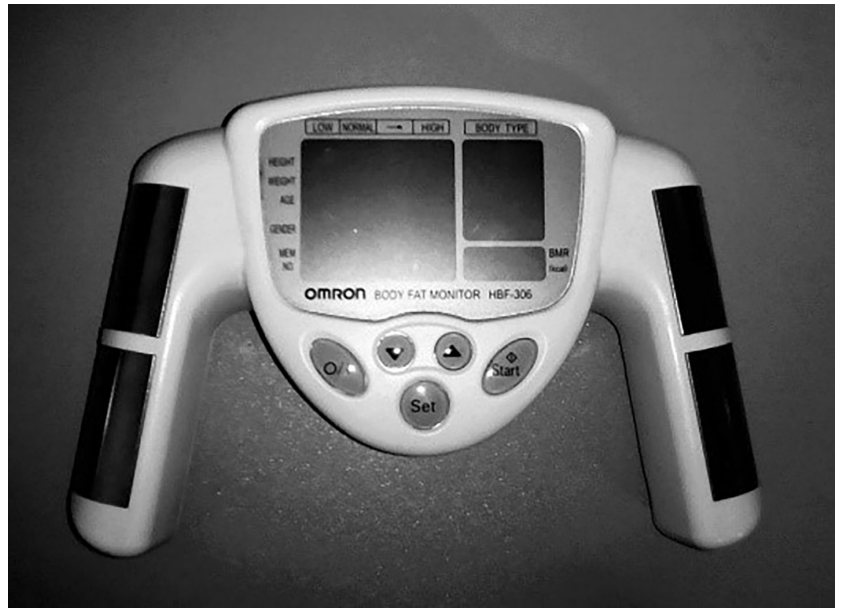

Figure 2. Handheld Bioelectric Impedance Device

\section{Study Procedures}

Methodological Framework and Design - the proponents make used of a reversal method (Table 1), quasi-experimental design and collection of data was done for eleven days with an observation-treatment cycle. Observations $(\mathrm{O})$ serve as the untreated test while the Treatments $(\mathrm{T})$ served as the post-test due to the inclusion of wave-synchronized music before their actual throws.

Table 1. Methodological Framework

\begin{tabular}{ccccccccccc}
\hline Day 1 & Day 2 & Day 3 & Day 4 & Day 5 & Day 6 & Day 7 & Day 8 & Day 9 & Day 10 & Day 11 \\
\hline O1 & O2 & T1 & O3 & O4 & T2 & O5 & O6 & T3 & O7 & T4 \\
& & W/ & & & W/ & & & W/ & W/ \\
& & Alpha & & & Alpha & & & Alpha & Alpha \\
& & Wave & & & Wave & & & Wave & Wave \\
\hline
\end{tabular}

Pre-collection Routine - Participants were oriented about the nature, procedure and potential benefits of the study. They were informed that collection of the data will be done before training time to ensure that participants are not weary from training.

\section{Collection of Data}

Observation Sessions (O) - Collection were done every 3 in the afternoon under tropical climate. There were 10-minute warm-up before 10-minute dynamic stretching sessions. Per- formance Trials were facilitated, with three trials of their best throwing event in between 5-minute rest intervals. Distance produced were recorded.

Treatment with Alpha Brainwave Synchronized (T1,2,4) During treatment days, same procedure was done for all participants. There was a twenty-minute listening to music synchronized with a $12 \mathrm{~Hz}$ soundwave (Alipoor, Oraki \& Sabet, 2014) concurrent to warming- up and stretching period. Implement used was based on the participant's best event, with 5-minute rest in between three trials. Distance produced were recorded. 
Treatment with Theta Brainwave Synchronized (T3) - During treatment days, same procedure was done for all participants. There was a twenty-minute listening to music synchronized with a $0.5-3 \mathrm{~Hz}$ soundwave (Alipoor et al., 2014) concurrent to warming- up and stretching period. Implement used was based on the participant's best event, with 5-minute rest in between three trials. Distance produced were recorded.

This study was cleared and approved by the University Ethics Board of Polytechnic University of the Philippines, complied to the proper procedures set by the mentioned body. The researchers solicited consent from the participants and university officials before the implementation of the study to ensure full protection of all human subjects prior to the study. Each participant voluntarily provided written, informed consent before participating. Adequate level of confidentiality was en-

Table 2. Demographic Profile of Participants sured and any type of communication in relation to the research work were done with integrity. Consent was part of screening, eligibility and qualification for participation.

\section{Statistical Treatment of Data}

The researchers used Wilcoxon Signed-Rank Test in analyzing the treated data from the experiment. Bar graphs were also presented in comparing means.

\section{Results}

Participants of the study were subjected to anthropometric measurements before the implementation of treatments and performance trials. Data indicated, as shown in Table 2, that male throwers are relatively muscular dominant comparing low percent body fat in relation to BMI and weight.

\begin{tabular}{lccccccccc}
\hline \multirow{2}{*}{ Variable } & \multirow{4}{*}{$\mathbf{N}$} & \multicolumn{4}{c}{ Males } & \multicolumn{5}{c}{ Females } \\
& & Mean & Std Dev & Min & Max & Mean & Std Dev & Min & Max \\
\hline Age & 3 & 19.67 & 1.53 & 18 & 21 & 20 & 1.73 & 19 & 22 \\
Weight & 3 & 77 & 6.93 & 73 & 85 & 78.33 & 26.35 & 49 & 100 \\
BMI & 3 & 25.73 & 3.47 & 22.5 & 29.4 & 28.4 & 8.39 & 19.1 & 35.4 \\
\%BF & 3 & 16 & 5.56 & 12.4 & 22.4 & 31 & 11.52 & 17.7 & 37.9 \\
\hline
\end{tabular}

Females expectedly scored higher in fat measurements compared to male counterparts. However, mean percent body fat of $31 \%$ is seen to be beyond normal for shotput female athletes using the standards presented by Jeukendrup and Gleeson (2010) with $20-28 \%$ for females and $16-20 \%$ for shotput male athletes. This also showed that male participants are within the normal standard in terms of body fat composition.

Aside from the high body fat percentage, it is also observable that the female group varied in terms of weight, BMI and $\% \mathrm{BF}$ compared to male participants, considering male groups'

heterogeneity composing of different type of events. Participants ranged from 18-22 yrs old.

Within the eleven-day investigation, a trend based on the mean performance was observed. Figure 3 shows the progression of performance with $(\mathrm{T})$ and without $(\mathrm{O})$ the inclusion of wave synchronizers. It shows consistent improvement in mean performance during three treatment days, specifically T1, T2 and T4, with $23.76 \mathrm{~m}, 24.25 \mathrm{~m}$ and $24.03 \mathrm{~m}$ respectively. Highest mean performance recorded were from $\mathrm{T} 2$, and $\mathrm{O} 6$ with $24.24 \mathrm{~m}$.

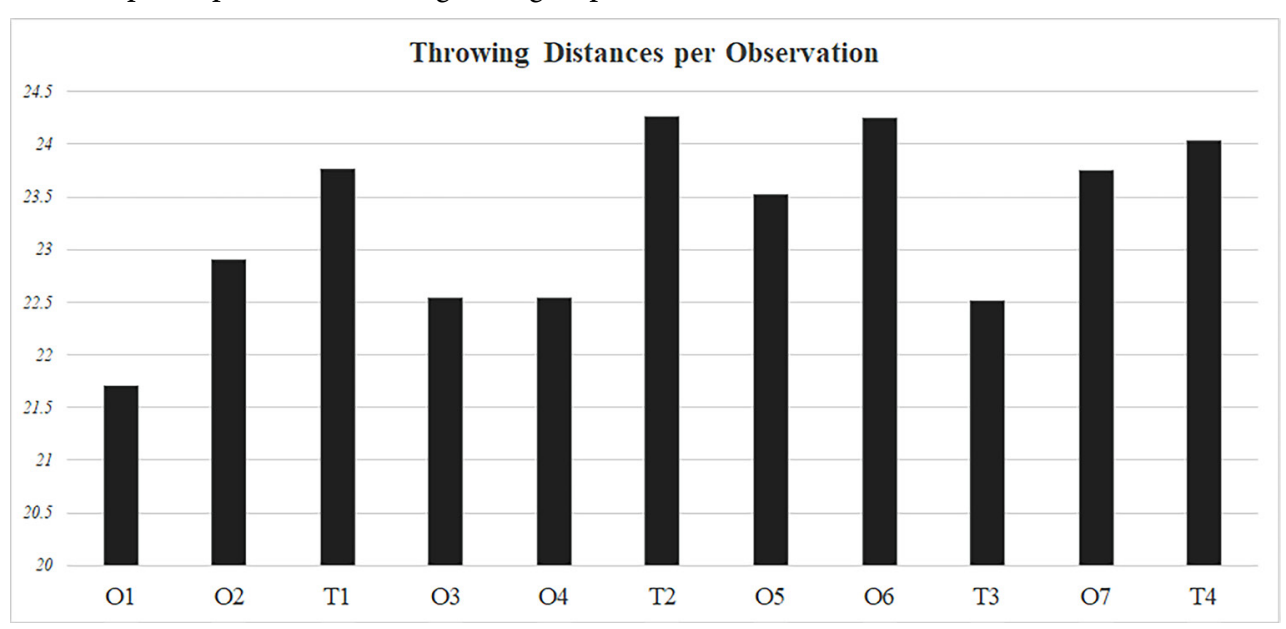

Figure 3. Mean Distance of Throws per Day of Observation Including Treatment Days

Mean throwing performance dropped when Theta Wave is introduced in the pre-trial routine during the third treatment day (T3) with $22.52 \mathrm{~m}$, compared to $23.52 \mathrm{~m}$ and $24.24 \mathrm{~m}$ records of $\mathrm{O} 5$ and $\mathrm{O} 6$ respectively. Figure 3 shows that T3 scores were even lower than O2 with $22.90 \mathrm{~m}$. Drop in mean performance did not manifest after a day without treatment $(\mathrm{O} 7)$ yielding a mean of $23.76 \mathrm{~m}$. It is observable also that mean performances of no-treatment days from $\mathrm{O} 1$ and $\mathrm{O} 6$ has an increasing trend.

Statistically comparing means of performance, Table 3 shows significant difference between the first alpha wave treatment (T1) and $\mathrm{O} 1$, \& $\mathrm{O} 2$. This significant change in performance was also observed in $\mathrm{O} 3$ when compared to the initial scores despite no alpha wave treatment. Observed significant change from $\mathrm{O} 2$ to $\mathrm{T} 1$ is consistent with the second alpha wave treatment (T2) when compared to O4. On the other hand, the visible drop from $\mathrm{O} 6$ to T3 is found to be statistically significant. T3 scores were also found significantly different when compared to scores acquired during O5. The rise in throwing distances with exclusion of theta waves at $\mathrm{O} 7$ is also significant. 
Table 3. Comparing differences using Wilcoxon Signed-Rank Test (W)

\begin{tabular}{ccccccccccc}
\hline & $\mathbf{O}_{2}$ & $\mathbf{T}_{1}$ & $\mathbf{O}_{3}$ & $\mathbf{O}_{\mathbf{4}}$ & $\mathbf{T}_{\mathbf{2}}$ & $\mathbf{O}_{\mathbf{5}}$ & $\mathbf{O}_{6}$ & $\mathbf{T}_{\mathbf{3}}$ & $\mathbf{O}_{\mathbf{7}}$ & $\mathbf{T}_{\mathbf{4}}$ \\
\hline $\mathrm{O}_{1}$ & -13 & $-15^{*}$ & $-15^{*}$ & - & - & - & - & - & - & - \\
$\mathrm{O}_{2}$ & - & $-15^{*}$ & 3 & - & - & - & - & - & - & - \\
$\mathrm{T}_{1}$ & - & - & $15^{*}$ & - & - & - & - & - & - & - \\
$\mathrm{O}_{3}$ & - & - & - & -1 & - & - & - & - & - & - \\
$\mathrm{O}_{4}$ & - & - & - & - & $-15^{*}$ & $-15^{*}$ & $-15^{*}$ & $\mathrm{TIE}$ & $15^{*}$ & $15^{*}$ \\
$\mathrm{~T}_{2}$ & - & - & - & - & - & 11 & 3 & $15^{*}$ & $\mathrm{TIE}$ & 7 \\
$\mathrm{O}_{5}$ & - & - & - & - & - & - & 5 & $15^{*}$ & -7 & -11 \\
$\mathrm{O}_{6}$ & - & - & - & - & - & - & - & $15^{*}$ & 9 & 3 \\
$\mathrm{~T}_{3}$ & - & - & - & - & - & - & - & - & $-15^{*}$ & $-15^{*}$ \\
$\mathrm{O}_{7}$ & - & - & - & - & - & - & - & - & - & $\mathrm{TIE}$ \\
\hline
\end{tabular}

Comparing untreated trials in between treatment days, no significant difference statistically observed between $\mathrm{O} 1$ \& $\mathrm{O} 2$ and O5 \& O6 particularly. During the two throwing days with the longest distances, no significant difference was found (between T2 and O6) despite one is treated and the other is not.

\section{Discussion}

Pre-competition music was seen to be exclusive as being a source of motivation (Laukka \& Quick, 2013) and affecting self-esteem and behavior (Elvers \& Steffens, 2017) for athletic performance. In this study, using music that is not self-selected and with the inclusion of soundwaves has presented links with throwing performance. Concurrent music and soundwave treatment with special attention to the latter as a variable infers music treatment for sports may be caused by several factors such as music preference, loudness, softness, aside from wave frequencies in it. Comparing with the study of Jarraya et al. (2012), increase in power output was observed only with the use of pre-competition music and no soundwave synchronization was specified, indicating that music alone can alter performance.

The contrast between alpha and theta waves in the study of Aris et al. (2010) was validated by the results of this study. The applicability of soundwaves in increasing physical performance is strong, particularly to those with power demands. Specifically in throwing, the needed optimal arousal (Judge et al., 2010) was linked to the concentration effects of alpha brainwaves. Entrainment through these soundwaves also explained the change in behavior (Stinson \& Arthur, 2013) and performance of athletes.

The relaxation and arousal effect to performance of soundwaves is also in accordance to the nature of a sport as found in a previous study when using music (Kuan et al., 2018). Optimal arousal demands of throwing can only be supported by soundwaves that promote arousal. In contrast, synchronizing relaxation waves may affect power performance, lessening stimulation, as seen in the trials of this study.

While the effect of two different soundwaves is presented in this study, an increasing trend of performance is also observed for trials with and without alpha wave synchronization. The indication of adaptation during the experiment was detected as part of the nature of a reversal design. Despite no alpha wave treatment, $\mathrm{O} 6$ scores were closely comparable to T4 scores. The possibility of soundwave lasting influence to performance is also noticed in the result.

After the 11-day investigation, synchronization of alpha wave in pre-performance music significantly increased throwing distances of male and female college athletes compared to the non-treatment counterparts. In contrast to this, significant drop in throwing distances were seen when theta wave was used during the warm-up (T4). While concurrent music and soundwave can be used to enhance performance, the researchers recommend that further studies be done comparing music with and without wave synchronizers, and focus on other variables within music used as well, such as preference, type of music, loudness, etc.

\section{Acknowledgements}

There are no acknowledgements.

\section{Conflict of Interest}

The authors declare that there are no conflicts of interest.

Received: 08 February 2019 | Accepted: 30 March 2019 | Published: 01 June 2019

\section{References}

Abeln, V., Kleinert, J., Strüder, H.K., \& Schneider, S. (2013). Brainwave entrainment for better sleep and post-sleep state of young elite soccer players - A pilot study. European Journal of Sport Science, 14(5), 393-402. doi: 10.1080/17461391.2013.819384

Alipoor, A., Oraki, M., \& Sabet, M.Y. (2014). Efficiency of brainwave entrainment by binaural beats in reducing anxiety. Journal of Kermanshah University of Medical Sciences, 18(1), 19-26.

Argento, E., Papagiannakis, G., Baka, E., Maniadakis, M., Trahanias, P., Sfakianakis, M., \& Nestoros, I. (2017). Augmented Cognition via Brainwave Entrainment in Virtual Reality: An Open, Integrated Brain Augmentation in a Neuroscience System Approach. Augmented Human Research, 2(1), $1-14$.

Aris, S.A.M., Lias, S., \& Taib, M.N. (2010). The relationship of alpha waves and theta waves in EEG during relaxation and IQ test. 2nd International Congress on Engineering Education (69-72), Kuala Lumpur, Malaysia.

Bargh, J.A. \& Cohen, J.L. (1978). Mediating Factors in the Arousal-Performance Relationship. Motivation and Emotion, 2(3), 243-257.

Brooks, K. \& Brooks, K. (2010). Enhancing sports performance through the use of music. Journal of exercise physiology online, 13(2), 52-58.

Cobar, A.G.C., Borromeo, M.C.B., Agcaoili, J.K.M., \& Rodil, A.M.T. (2017). Acute effect of birdwatching on mood states of senior high school students in the physical education setting. Ovidius University Annals, Series Physical Education and Sport/Science, Movement and Health, 17(1), 18-25.

Cobar, A.G.C. \& Madrigal, N. (2016). Effect of Endurance Training with Weighted Vest on the 3000-Meter Running Time of High School Boys. Journal of Physical Education and Sport, 16(2), 301-310. doi:10.7752/ jpes.2016.02048.

Cruceanu, V.D. \& Rotarescu, V.S. (2013). Alpha brainwave entrainment as a cognitive performance activator. Cognitie, Creier, Comportament/Cognition, Brain, Behavior, 17(3), 249-261.

Elvers, P. \& Steffens, J. (2017). The sound of success: Investigating cognitive and behavioral effects of motivational music in sports. Frontiers in Psychology, 8, 1-11. doi:10.3389/fpsyg.2017.02026/full

Huang, T.L. (2008). A comprehensive review of the psychological effects of brainwave entrainment. Alternative Therapies in Health and Medicine, 14(5), 38-50.

Karageorghis, C.I., Priest, D.L., Williams, L.S., Hirani, R.M., Lannon, K.M., \& Bates, B.J. (2010). Ergogenic and psychological effects of synchronous music during circuit-type exercise. Psychology of Sport and Exercise, 551559. 
Kuan, G., Morris, T., Kueh, Y.C., \& Terry, P.C. (2018). Effects of Relaxing and Arousing Music during Imagery Training on Dart-Throwing Performance, Physiological Arousal Indices, and Competitive State Anxiety. Frontiers in Psychology, 9, 1-12. doi 10.3389/fpsyg.2018.00014

Jarraya, M., Chtourou, H., Aloui, A., Hammouda, O., Chamari, K., Chaouachi, A., \& Souissi, N. (2012). The effects of music on high-intensity short-term exercise in well trained athletes. Asian journal of sports medicine, 3(4), 233.

Jeukendrup, A. \& Gleeson, M. (2010). Chapter 13-Body Composition: Chapter taken from Sport Nutrition: An Introduction to Energy Production and Performance, 2nd ed: Human kinetics.

Judge, L.W., Bell, R.J., Bellar, D., \& Wanless, E. (2010). Developing a Mental Game Plan: Mental Periodization for Achieving a "Flow" State for the Track and Field Throws Athlete. Sport Journal, 13(4), 1-10.

Laukka, P. \& Quick, L. (2013). Emotional and motivational uses of music in sports and exercise: A questionnaire study among athletes. Psychology of Music, 41(2), 198-215. doi: 10.1177/0305735611422507

Li, Y., Tseng, C., Tsai, A.C., Huang, A.C., \& Lin, W. (2016). Different Brain Wave Patterns and Cortical Control Abilities in Relation to Different Creative Potentials. Creativity Research Journal, 28(1), 89-98. doi:10.108 $0 / 10400419.2016 .1125255$

Moulton, A. (2013). Effect of accurate categorical activity selection on the prediction of percent body fat when using the Omron HBF-306 bioelectric impedance analyzer. Masters Theses.

Pelka, M., Kolling, S., Ferrauti, A., Meyer, T., Pfeiffer, M., \& Kellman, M. (2017). Acute effects of psychological relaxation techniques between two physical tasks. Journal of Sports Sciences, 35(3), 216-223.

Robinson, D.L. (2000). The technical, neurological, and psychologica significance of 'alpha', 'delta' and 'theta' waves confounded in EEG evoked potentials: a study of peak amplitudes. Personality and Individual Differences, 28(4), 673-693.

Sammy, N., Anstiss, P.A., Moore, L.J., Freeman, P., Wilson, M.R., \& Vine, S.J. (2017). The effects of arousal reappraisal on stress responses, performance and attention. Anxiety, Stress \& Coping: An International Journal, 30(6), 619-629.

Simpson, S.D. \& Karageorghis, C.I. (2006). The effects of synchronous music on 400-m sprint performance. Journal of sports sciences, 24(10), 1095-1102.

Stinson, B. \& Arthur, D. (2013). A novel EEG for alpha brain state training, neurobiofeedback and behavior change. Complementary Therapies in Clinical Practice, 19(3), 114-8. doi:10.1016/j.ctcp.2013.03.003

Terry, P., Karageorghis, C., Saha, A, \& D' Auria, S. (2012). Effects of synchronous music on treadmill running among elite triathletes. Journal of Science and Medicine in Sport, 15(1), 52-57.

Turner, P. E. \& Raglin, J. S. (1996). Variability in precompetition anxiety and performance in college track and field athletes. Medicine and Science in Sports and Exercise, 28(3), 378-85.

Viola, A.U., James, L.M., Schlangen, L.J.M., \& Dijk, D.J. (2008). Blue-enriched white light in the workplace improves self-reported alertness, performance and sleep quality. Scandinavian Journal of Work, Environment \& Health, 34(4), 297-306 